\title{
Curriculum Integration in Medical Education: A Theoretical Review
}

Hani S Atwa ${ }^{1,2^{*}}$ and Enas M Gouda ${ }^{2}$

${ }^{1}$ Ibn Sina National College for Medical Studies, Jeddah, Saudi Arabia

${ }^{2}$ Suez Canal University, Egypt

*Corresponding author: Hani S Atwa, Ibn Sina National College for Medical Studies, Jeddah, Saudi Arabia; Tel: 201224576171/966593763061; E-mail: doctorhani2000@yahoo.com

Rec date: Mar 5, 2014; Acc date: Mar 26, 2014; Pub date: April 1, 2014

Copyright: (C) 2014 Hani SA, et al. This is an open-access article distributed under the terms of the Creative Commons Attribution License, which permits unrestricted use, distribution, and reproduction in any medium, provided the original author and source are credited.

\begin{abstract}
Integration seeks to break down the barriers between the subject areas in order to provide students with better learning opportunities that facilitate the development of knowledge that is relevant and meaningful to clinical practice, deep and retrievable, and amenable to alteration, updating, and development as a part of an ongoing process of lifelong learning.

The subject of curriculum integration has been under discussion off and on for the last half century, with a resurgence occurring over the past decade. The "explosion" of knowledge, the increase of state mandates related to myriad issues, fragmented teaching schedules, concerns about curriculum relevancy, and a lack of connections and relationships among disciplines have all been cited as reasons for a move towards an integrated curriculum.
\end{abstract}

Keywords Integration; Curriculum; Course; Discipline; Cognitive; Medical education; Learning theories

\section{Definition of Integration}

The most prominent models for integration discussed over the past few decades were the Integration Ladder introduced by Ronald Harden et al. [1] and the Ten Ways to Integrate Curriculum described by Robin Fogarty et al. [2]. Those two most common continuums of methodologies for integration will be discussed in our review (Figure $1)$.

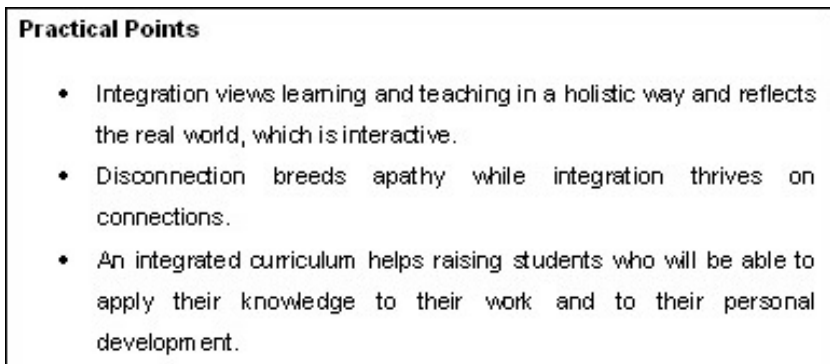

- An integrated curriculum helps raising students who will be able to apply their knowledge to their work and to their personal development.

Figure 1: Integration defined.

Shoemaker et al. [3] defined an integrated curriculum as "education that is organized in such a way that it cuts across subject-matter lines, bringing together various aspects of the curriculum into meaningful association to focus upon broad areas of study". It views learning and teaching in a holistic way and reflects the real world, which is interactive.

In the integrative curriculum, the planned learning experiences not only provide the learners with a unified view of commonly held knowledge but also motivate and develop learners' power to perceive new relationships and thus to create new models, systems, and structures [4].

Curriculum integration can be described as an approach to teaching and learning that is based on both philosophy and practicality. It can generally be defined as a curriculum approach that purposefully draws together knowledge, skills, attitudes and values from within or across subject areas to develop a more powerful understanding of key ideas. Curriculum integration occurs when components of the curriculum are connected and related in meaningful ways by both the students and teachers [5].

Horizontal integration brings together the disciplines, topics, and subject. It refers to the provision of learning within the structure where individual departments/subject areas contribute to the development and delivery of learning a meaningful, holistic manner. By this process and links are made between the different subject areas and that learning is enriched by the connections and interrelationships being made explicit [5].

Vertical integration brings together basic and clinical sciences. It refers to combination of basic and clinical sciences in such a way that the traditional divide between preclinical and clinical studies is broken down, therefore basic science is represented explicitly in the curriculum within the clinical environments during all the years of undergraduate education and beyond into postgraduate training and continuing professional development. This means that the learning of basic science is placed in the context of clinical and professional practice and seen to be more meaningful and relevant to students [5]. Curriculum integration usually involves both horizontal and vertical integration and is the pattern that is becoming widespread throughout the world.

Our review will focus mainly on integration of the preclinical (basic) medical sciences. 


\section{Background}

Integration is around us everywhere in society and in nature. Most contemporary jobs require the integration of a range of skills. In today's workforce, we are given a problem and asked to solve it. In traditional schools students are given a set of facts, asked to memorize them, but then are not given the opportunity to apply them in a way that is applicable to life outside of the school. Disconnection breeds apathy while integration thrives on connections [6].

The movements toward a global economy and international connections, as well as the rapid changes in technology, are pushing education toward integration. The ability to make connections, to solve problems by looking at multiple perspectives, and to incorporate information from different fields, will be an essential ingredient for success in the future. An enduring argument for integration is that it represents a way to avoid the fragmented and irrelevant acquisition of isolated facts, transforming knowledge into personally useful tools for learning new information [7].

Integrated curricula have been widely adopted, fuelled by dissatisfaction with the way basic sciences have been taught as individual disciplines with no clinical application and by growing recognition that the traditional instructional modes no longer meet current demands for interdisciplinary inquiry and practice in medicine $[8,9]$. At the same time, cognitive theories of learning suggest that an integrated approach to education may have important benefits for learning and retention because it facilitates contextual and applied learning, and can promote development of the well-organized knowledge structures that underlie effective clinical reasoning [10-13].

Traditional pre-clerkship curricula, with each science discipline offering its content from within a departmental silo, frequently fail learners as they advance to the clinical years. Information presented without robust cross-links and ties to clinical applications, and tested in isolation from related subject matter, has proven difficult for students to recall after the transition to clinical clerkships [14].

The movement towards integrated curriculum is a move away from memorization and recitation of isolated facts and figures to more meaningful concepts and the connections between concepts. The twenty-first century requirement for a flexible use of knowledge goes beyond a superficial understanding of multiple isolated events to insights developed by learning that is connected-(Or) integrated [4].

\section{History}

Since the time of Flexner, the basic science medical school curriculum has largely consisted of discrete courses controlled by individual departments [8]. Such curricula have largely included an initial phase focused on normal structure and function followed by a pathophysiology phase, sometimes organized around organ systems or taught during core clinical rotations [15].

Dissatisfaction with this curricular model has included students' complaints about lack of relevance and faculty members' concerns about students' failure to recall relevant basic science knowledge during their clinical education. Medical students have viewed the basic science curriculum as a hurdle to be overcome in order to earn the right to step onto the hospital wards and clinical teachers have complained that when students arrive on the clinical rotations, they have no intellectual curiosity, having spent the first phase of medical school memorizing unrelated facts rather than learning to think like a clinician [15].
In 1969, McMaster Medical School challenged the assumption that students could only learn basic science by listening to the experts; faculty replaced the traditional lecture and laboratory basic science curriculum with problem-based learning (PBL) in which small groups of students working with cases and problems under the guidance of a faculty tutor could be trusted to identify essential learning questions and educate themselves through independent and peer teaching [16]. Few medical schools in North America were willing to adopt this curricular model until Harvard Medical School created a hybrid curriculum in 1985 that combined PBL with limited lectures and laboratories in order to help students develop a flexible, integrated knowledge base [17].

Using a block structure rather than concurrent courses to promote integration and encouraging partnerships between basic science and clinical faculty members in designing these blocks, Harvard demonstrated that students could learn basic science in the context of clinical medicine and humanistic care while maintaining sufficient content mastery to pass the national licensing examination with no decrement in basic science knowledge [18]. The prevailing trend in basic science curriculum change around the world is now towards integration, both horizontally among disciplines and vertically between basic and clinical sciences, often including PBL as an integrative function [19].

\section{Benefits of Integrative Approach to Curriculum Planning}

Many teachers in the primary grades cite the following benefits of an integrative approach to curriculum and planning.

\section{Allowing for flexibility:}

Through curriculum integration, teachers can plan for the development of key skills and understandings that transcend individual strands and subjects.

\section{Building on prior knowledge and experiences:}

Choosing meaningful connections among subject areas helps students build on their diverse prior knowledge and experiences, supports their holistic view of the world and ensures more meaningful learning.

\section{Unifying the students' learning}

Curriculum integration enables students to develop a unified view of the curriculum to broaden the context of their learning beyond single subject areas.

\section{Reflecting the real world}

When curriculum is organized in a holistic way, it better reflects the real world and the way children learn at home and in the community

Matching the way students think:

Brain research supports the theory that younger students take in many things and process and organize them at one time. Teaching ideas holistically, rather than in fragmented pieces, better reflects how young students' brains process information [5].

\section{Requirements for Integration}

1. Effective management of change: Shifting the curriculum from one state (fragmentation) to another (integration) is a major issue that 
needs careful management by the curriculum administrators and also needs full understanding and support by everyone in the institution.

2. In-depth review the curriculum: to be able to plan and implement a successful integration in the curriculum, every component of the curriculum and every curriculum area should be properly mapped and documented.

3. Commitment of faculty, departments, and individuals, and development

teams and structures to support planning and implementation.

4. Agreement on the degree and type (horizontal and vertical) of integration: the level of integration should be agreed upon by faculty, departments, and individuals based on the feasibility and resources available. Sometimes, partial integration is better adopted as a beginning and the level can be increased gradually by time. This is true especially in well-established institutions. In newly-established ones, a fully integrated curriculum may be planned from the beginning; so long the resources are available. Also, integration may be started as horizontal in the basic medical sciences as a prototype for further integration (horizontal between clinical sciences and vertical between basic and clinical sciences) [6].

\section{Methodologies of Integration}

In this paper, the two most common continuums of methodologies for integration $[1,2]$ will be described.

\section{Fogarty methodologies for integration:}

Fogarty et al. [2] has described ten levels of integration, grouped under three forms.

\section{Form One: Within a Single Discipline}

\section{Fragmented}

1. Description: The fragmented methodology is a traditional curriculum design which separates topics and courses into distinct disciplines. In this model courses are separated into traditional areas of study. Each area is defined as an independent course of study.

2. Advantages: Clear and discrete view of a discipline to the students.

3. Disadvantages: Connections are not made clear for students; less transfer of learning.

\section{Connected}

1. Description: A connected methodology focuses on the details, subtleties, and interconnections within an individual discipline. It is this focus on making connections (i.e., one topic to another, one skill to another or one concept to another) which makes this methodology a simple form of integration. It is important to the concept of integration that this methodology directly relates ideas within a discipline.

2. Advantages: Key concepts are connected leading to the review, reconceptualization, and assimilations of ideas within a discipline.

3. Disadvantages: Disciplines are not related; contents focus remains within the discipline.

\section{Nested}

1. Description: Nested integration takes advantage of natural combinations. Integration is performed by overtly making connections or creating combinations.

2. Advantages: Gives attention to several areas at once, leading to enriched and enhanced learning.

3. Disadvantages: Students may be confused and lose sights of the main concepts of the activity or lesson.

\section{Form Two: Across the Disciplines}

\section{Sequenced}

1. Description: Topics and units are taught independently, but they are arranged and sequenced to provide a framework for related concepts. Teachers arrange topics so that similar units articulate.

2. Advantages: Facilitates transfer of learning across content areas.

3. Disadvantages: Requires ongoing collaboration and flexibility, as teachers have less autonomy in sequencing curricula.

\section{Shared}

1. Description: The shared model brings two distinct disciplines together into a single focus. The shared methodology overlaps concepts as the organizer.

2. Advantages: Shared instructional experiences; with two teachers on a team it is less difficult to collaborate.

3. Disadvantages: requires time, flexibility, commitment and compromise.

\section{Webbed}

1. Description: Thematic teaching, using a theme as a base for instructions in many disciplines.

2. Advantages: Motivating for students; helps them see connections between ideas.

3. Disadvantages: Theme must be carefully and thoughtfully selected to be meaningful, with relevant and rigorous content.

\section{Threaded}

1. Description: The threaded approach to integration is a metacurricular approach where big ideas are enlarged. This methodology threads thinking skills, social skills, study skills, graphic organizers, technology, and multiple intelligences approach to thinking throughout all disciplines. The threaded approach supersedes all subject matter content. Using this approach, interdepartmental teams can focus on thinking skills to integrate with content information. The threaded approach takes learning to a synthesis level.

2. Advantages: Students learn how they are learning, facilitating future transfer of learning.

3. Disadvantages: Disciplines remain separate. 


\section{Integrated}

1. Description: In an integrated methodology interdisciplinary topics are arranged around overlapping concepts and emergent patterns. This process blends the disciplines by finding overlapping skills, concepts, and attitudes found across the disciplines. Much like the shared methodology, integration is a result of shifting related ideas out of the subject matter content. An important process of the integrated methodology is that teachers work together on the topics or themes as commonalities emerge.

2. Advantages: Encourage students to see interconnectedness and interrelationships among disciplines, students are motivated as they see these connections.

3. Disadvantages: Requires interdepartmental teams with common planning and teaching times.

\section{Form Three: Within and Across Learners}

\section{Immersed}

1. Description: The immersed methodology focuses all curricular content on interest and expertise. With this methodology, integration takes place within the learners, with little or no outside intervention. This immersed study is often undertaken in a field of intense interest or passion.

2. Advantages: Integration takes place within the learner.

3. Disadvantages: May narrow the focus of the learner.

\section{Networked}

1. Description: A networked methodology creates multiple dimensions and directions of focus. Like brainstorming, it provides various ideas and ways of discovering. The networked methodology is totally student centered. It professes that only the learner can direct the integration process. The methodology proposes that the learner knows their topic and can self-direct their focus on the necessary resources both within and across subject areas.

2. Networks are created between the learner and various information systems, subject matter experts, and others who have an interest, experience or knowledge of the topic or theme.

3. Advantages: Pro-active, with learner stimulated by new information, skills and concepts.

4. Disadvantages: Learner can be spread too thin, efforts become ineffective.

\section{Harden Methodologies for Integration: "The Integration Ladder"}

Harden et al. [1] argues that curricular integration can be viewed as a ladder, with discipline-based teaching (isolation) at the bottom of the ladder and full integration (trans-disciplinary teaching) at the top.

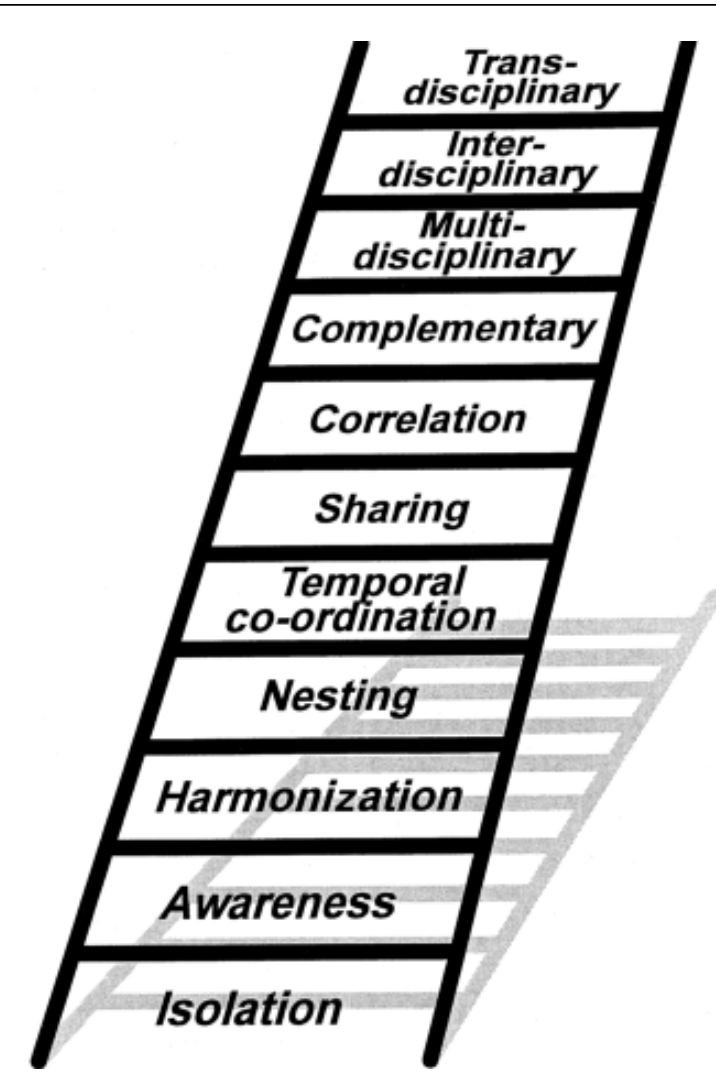

Figure 2: The Integration Ladder.

(Courtesy of Professor Ronald Harden et al. [1])

The integration ladder (Figure 2) has eleven steps from subjectbased to integrated teaching and learning. In the first four steps on the ladder, the emphasis is on the subjects or disciplines. Moving up the ladder, the following six steps emphasize integration across several disciplines. In the final step, the student takes more responsibility for the integration and is given the tools to do so [1].

\section{Step 1: Isolation/fragmentation}

1. Description: Departments or subject specialists organize their teaching without consideration of other subjects or disciplines. Each discipline looks, from the perspective of their own discipline, at the curriculum content in terms of areas to be covered, depth of coverage, sequence and timing. This isolation approach may be found in the traditional medical curriculum with blocks of time allocated to the individual disciplines. Students attend a lecture on anatomy, and then move on to a lecture in physiology with neither lecturer being aware of what was covered in the other lecture.

2. Advantages: Disciplines are retaining their boundaries so content is kept clear and intact.

3. Disadvantages: No attention is paid to other, or related, subjects which contribute to the curriculum. Each subject is seen as an entity in itself. The relationships between subjects are not explicitly covered and related topics from two disciplines are not intentionally correlated. 


\section{Step 2: Awareness}

1. Description: As with isolation, the teaching is subject-based. However, some mechanisms are in place whereby the teacher in one subject is made aware of what is covered in other subjects in the curriculum. This can be achieved through appropriate documentation and communication about the aims and objectives of each course and the content and topics covered in lectures and other teaching sessions. Lecture notes or handouts may be circulated to other course teachers as well as to students.

2. Advantages: The teacher can take account of what colleagues cover in other parts of the course when planning his or her teaching, avoiding unnecessary duplication or redundancy and cross-referring, where appropriate, to other parts of the course.

3. Disadvantages: There is no explicit attempt to help the student to take an integrated view of the subject.

\section{Step 3: Harmonization/consultation}

1. Description: In harmonization, teachers responsible for different courses or different parts of the same course consult each other and communicate about their courses. The consultation process takes place through informal discussions between teachers or through more formal curriculum planning committees and meetings. The consultation may involve individual teachers or groups of teachers. The process of consultation may be overseen by a member of staff who has some overall responsibility for the curriculum and who has the facilitation or organization of discussion between teachers from different subjects.

2. Advantages: Encourages teachers to adapt their programs so that each course makes an appropriate contribution to the curriculum and the overall curriculum objectives are more likely to be achieved.

\section{Disadvantages: Disciplines remain separate.}

\section{Step 4: Nesting/infusion}

1. Description: Content drawn from different subjects in the curriculum may be used to enrich the teaching of one subject. The term "infusion" has also been applied to this stage of integration where teachers "analyze" the separate subject's goals and identify ways in which these generic skills can be refined into existing subjects.

2. Advantages: Individual subjects or disciplines recognize the broader curriculum outcomes and relate their teaching program to these. They may do this by arranging content specific inputs from other parts of the course into the subject's teaching program, and by recognizing the generic competencies, such as communication and problem-solving skills, to be acquired in the program.

3. Disadvantages: Teaching remains subject-based and the course is the responsibility of and in the control of the subject or discipline.

\section{Step 5: Temporal co-ordination/parallel teaching}

1. Description: Each subject remains responsible for its own teaching program. The timing of the teaching of topics within a subject, however, is done in consultation with other disciplines. The timetable is adjusted so that topics within the subjects or disciplines which are related are scheduled at the same time. Similar topics are taught on the same day or week while remaining part of a subjectbased teaching program. Students study the concepts of the different subjects separately, and are left themselves to uncover the relationships. This approach has been described also as "parallel" or "concurrent" teaching.

2. Advantages: Programs described as "integrated teaching programs" are often, in practice, programs which are temporally coordinated. The implementation of a temporally coordinated program introduces some of the advantages of integrated teaching and is a good stepping off point for a more integrated curriculum.

3. Disadvantages: Teaching is not fully integrated and disciplines still retain, to a great extent, their fragmented nature.

\section{Step 6: Sharing/joint teaching}

1. Description: Two disciplines may agree to plan and jointly implement a teaching program. The "shared planning and teaching" takes place in two disciplines in which overlapping concepts or ideas emerge as organizing elements'[3]. The two disciplines which come together to offer such a program are usually complementary subjects and the joint course produced emphasizes shared concepts, skills, and attitudes. The focus of the course is usually in these shared elements. The impetus for shared programs often comes from the subjects or departments themselves, through the identification of common areas of teaching or the need to include a new topic in the curriculum. The departments appreciate that together they can teach the subject better, more effectively, and more efficiently than either could alone.

2. Advantages: Unlike temporal co-ordination, which may be a step towards a more fully integrated overall program, shared programs are often seen as ends in themselves. They tend to be perceived as special cases which, even if they are successful, are not necessarily examples to be followed in other parts of the curriculum. Occasionally, however, this is not so and a shared program may be a step towards more complete integration.

3. Disadvantages: Not all disciplines are fit for this type of integration. The two disciplines should have overlapping concepts and ideas. Again, the integration is not fully emphasized here.

\section{Step 7: Correlation/concomitant program}

1. Description: The emphasis remains on disciplines or subjects with subject-based courses taking up most of the curriculum time. This session brings together areas of interest common to each of the subjects.

2. Advantages: Within this framework, an integrated teaching session or course is introduced in addition to the subject-based teaching.

3. Disadvantages: The integrated disciplines should have areas of common interest. Also, the integration is not fully emphasized, as the emphasis is still on the separate disciplines or subjects.

\section{Step 8: Complementary/mixed program}

1. Description: This approach has both subject-based and integrated teaching. The integrated sessions now represent a major feature of the curriculum. These sessions are recognized to be, in terms of time, allocated resources and assessment as important, if not more important, than the subject-based teaching. The focus for the teaching may be a theme or topic to which the disciplines can contribute. Running alongside the integrated teaching are scheduled opportunities for subject-based teaching. 
2. Advantages: Student assessment strategies in this approach stresses on both the integrated and fragmented parts of the curriculum.

3. Disadvantages: A great part of the curriculum is subject-based, and integration runs as a parallel track alongside the separate disciplines.

\section{Step 9: Multi-disciplinary/webbed}

1. Description: A multidisciplinary approach (termed "webbed" by Fogarty) brings together a number of subject areas in a single course with themes, problems, topics, or issues as the focus for the students' learning. The themes selected as the focus in an integrated course may function in different ways. The themes can delineate an area in which practical decisions have to be made and which serve as a focal point of interdisciplinary thinking. Tasks to be undertaken by the professional may also be used as a focus for integrated teaching. In task-based learning within this approach, the learning is concerned not only with mastery of the tasks but with learning related to the tasks, including an understanding of the relevant basic and applied medical sciences. In multidisciplinary teaching, the contributions of the individual disciplines to the theme are stated implicitly in the curriculum documents and the timetables.

2. Advantages: The subjects and disciplines give up a large measure of their own autonomy.

3. Disadvantages: The disciplines preserve their identity and each demonstrates how their subject contributes to the student's understanding of the theme or problem. Still, themes are viewed through the lens of subjects or disciplines.

\section{Step 10: Inter-disciplinary/monolithic}

1. Description: In interdisciplinary integration there is a further shift of emphasis to themes as a focus for the learning of and to the commonalties across the disciplines or subjects as they relate to the theme. Jarvis et al. [20] defines interdisciplinary as 'a study of a phenomenon that involves the use of two or more academic disciplines simultaneously (monolithic)'.

2. Advantages: Implicit in the move from a multidisciplinary to an interdisciplinary approach may be the loss of the disciplines' perspectives.

3. Disadvantages: In the interdisciplinary course there may be no reference to individual disciplines or subjects, and subjects are not identified as such in the timetable.

\section{Step 11: Trans-disciplinary/authentic/fusion/immersion}

1. Description: In trans-disciplinary, as in interdisciplinary integration, the curriculum transcends the individual disciplines. The focus with trans-disciplinary integration for learning, however, is not a theme or topic selected for this purpose, but the field of knowledge as exemplified in the real world. The teacher provides a structure or framework of learning opportunities, but the integration is done in the mind of the student, based on hi-fidelity situations in the real world of clinical care. Trans-disciplinary education is reflected in learning described by McCombs et al. [21] as an individual process of constructing meaning from information and experience, filtered through each individual's unique perceptions, thoughts and feelings.' Thus, in a trans-disciplinary approach the disciplines become part of the learner's real world experience and through these they filter the broader aims and goals of the integrated curriculum. In this environment, the learner is driven to find out as dictated by the prescribed tasks. This stage of integration has been termed 'authentic' integration, reflecting that the learning occurs in the real world. The term 'fusion' has also been applied to this stage. As the student learns, he or she integrates internally and intrinsically and completes the mastery of the competencies related to the task. Fogarty et al. [22] uses the term 'immersion' when 'disciplines become part of the learner's experience and through these filter the broader aims and goals'.

2. Advantages: Maximally resembles the real world situations. Experiences learned through it are thought to be easily incorporated into the learner's metacognition and set of values and attitudes.

3. Disadvantages: it is difficult to achieve and needs tremendous collaborative efforts from the sides of the curriculum planners and subject area experts. Also, its success depends mainly on the learners and their degree of readiness to learn through such highly integrative approach.

\section{Conclusion}

Integrating a curriculum is a complex process. It is differentially understood and experienced by students and faculty, and can refer to instructional method, content, faculty work or synthesis of knowledge in the minds of learners. It can occur at different rates and some subjects are integrated more easily than others. An integrated curriculum holds much promise for raising students, who will be able to apply their school-acquired knowledge to their work and to their personal development.

\section{Acknowledgement}

All praise and gratitude is to Allah. We also would like to thank everyone who gave us hand in writing this article.

\section{References}

1. Harden RM (2000) The integration ladder: a tool for curriculum planning and evaluation. Med Educ 34: 551-557.

2. Fogarty R (1991) Ten ways to integrate curriculum. Educational Leadership 49: 61-65.

3. Shoemaker BJE (1989) Integrative Education: A Curriculum for the Twenty-First Century. Oregon School Study Council 33: 1-46.

4. Merickel ML (1998) Integration of the Disciplines: Ten Methodologies for Integration.

5. Alberta Education Guide (2007) Primary Programs FrameworkCurriculum Integration: Making Connections. Alberta Education, Alberta, Canada.

6. Bradley P, Mattick K (2008) Integration of basic and clinical sciences AMEE, 2008.

7. Lipson M, Valencia S, Wixson K, Peters C (1993) Thematic Teaching: Integration to Improve Teaching and Learning. Language Arts 70: 252-264.

8. Cooke M, Irby DM, Sullivan W, Ludmerer KM (2006) American medical education: 100 years after the Flexner report. N Engl J Med 355: 1339-1344.

9. Custers E, Cate OT (2002) Medical students' attitude towards and perception of the basic sciences: a comparison between students in the old and new curriculum at the University Medical Centre Utrecht, the Netherlands. Med Educ 36: 1142-1150.

10. Mann KV (2002) Thinking about learning: implications for principlebased professional education. J Contin Educ Health Prof 22: 19-26. 
Citation: Atwa HS, Gouda EM (2014) Curriculum Integration in Medical Education: A Theoretical Review. Intel Prop Rights 2: 113. doi:10.4172/ 2375-4516.1000113

Page 7 of 7

11. Vidic B, Weitlauf HM (2002) Horizontal and vertical integration of academic disciplines in the medical school curriculum. Clin Anat 15: 233-235.

12. Regehr G, Norman GR (1996) Issues in cognitive psychology: implications for professional education. Acad Med 96: 988-1002.

13. Bordage G (1994) Elaborated knowledge: a key to successful diagnostic thinking. Acad Med 69:883-885.

14. Prince KJ, van de WM, Scherpbier AJ, Vleuten CP, Boshuizen HP (2000) A qualitative analysis of the transition from theory to practice in undergraduate training in a PBL medical school. Adv Health Sci Educ 5: 105-116.

15. Wilkerson L, Stevens CM, Krasne S (2009) No content without context: Integrating basic, clinical, and social sciences in a pre-clerkship curriculum. Med Teach 31: 812-821.

16. Barrows HS, Tamblyn RM (1980) Problem-Based Learning: An Approach to Medical Education. Springer Publishing Company, New York.
17. Moore GT, Block SD, Style CB, Mitchell R (1994) The influence of the new pathway curriculum on Harvard medical students. Acad Med 69: 983-989.

18. Moore GT (1995) The first curriculum: Content and process. In: Tosteson DC, Adelstein SJ, Carver ST, editors. New Pathways to medical education: Learning to learn at Harvard Medical School. Cambridge MA: Harvard University Press.

19. Harden RM, Sowden S, Dunn WR (1984) Education strategies in curriculum development: The SPICES model. Med Educ 18: 284-297.

20. Jarvis P (1990) An international Dictionary of Adult and Continuing Education. London and New York: Routledge.

21. McCombs BL (1992) Learner-Centered Psychological Principles. Guidelines for School Redesign and Reform. Washington DC: American Psychological Association.

22. Fogarty R (1991a) The Mindful School: How to Integrate the Curricula. Palatine, IL: Skylight Publishing. 